\title{
The Norwegian eHealth Platform: Development Through Cultivation Strategies and Incremental Changes
}

\author{
Miria Grisot, Polyxeni Vassilakopoulou, \\ and Margunn Aanestad
}

\subsection{Introduction}

This chapter presents the approach followed for the development of the Norwegian national solution for patient-oriented eHealth services (here called HealthNorway). Our research interest is twofold: first, on understanding the initial design decisions and initial evolution in relation to the installed base of existing digital capabilities, and, second, on understanding how HealthNorway was further developed after the initial launch in relation to the long term vision of offering comprehensive and readily available health services to citizens. Drawing from the case, we identify different approaches for infrastructural development in the form of proactive cultivation strategies related to extending, complementing and creating substitutes within the installed base.

The remainder of the chapter is structured as follows: we provide first a brief overview of the Norwegian health system and its digital infrastructure; we then introduce our case and present key activities, concerns and decisions for HealthNorway

\footnotetext{
M. Grisot $(\triangle)$

Department of Informatics, University of Oslo, Postboks 1080, Blindern, 0316 Oslo, Norway e-mail: miriag@ifi.uio.no

P. Vassilakopoulou

Department of Information Systems, University of Agder,

Postboks 422, 4604 Kristiansand, Norway

Department of Informatics, University of Oslo, Postboks 1080, Blindern, 0316 Oslo, Norway e-mail: polyxenv@uia.no

M. Aanestad

Department of Informatics, University of Oslo, Postboks 1080, Blindern, 0316 Oslo, Norway

UIT The Arctic University of Norway, Postboks 6050, Langnes, 9037 Troms $\varnothing$, Norway

e-mail: margunn@ifi.uio.no
} 
development. Afterwards, we analyse the different approaches that were followed for relating to the installed base. We conclude by discussing our findings.

\subsection{Norwegian Healthcare}

\subsubsection{Overview of the Norwegian Healthcare Model}

Norway has a predominantly public healthcare sector, where the National Insurance Act guarantees every citizen access to healthcare services paid by the state. Inpatient hospital care is free, while there are consultation fees for physician visits and outpatient treatment, and payment for prescription drugs up to a limit. The patients have free choice of hospitals, but General Practitioners (GPs) serve as gatekeepers for referrals to hospitals or specialists. The specialist healthcare including hospitals and psychiatric care is governed by the Ministry of Health, through four regional Health Authorities established in 2002 (Region West, South-East, Middle and North). These authorities govern also the ICT investments in clinical and administrative systems within their region.

Primary healthcare is offered at the municipal level; GPs, antenatal and postnatal care, immunization and care for the sick and elderly at home or in nursing homes. The municipalities' autonomy is strong, and they make their own ICT investments. In 2008, the Coordination reform, has targeted the less than optimal collaboration between specialist and primary healthcare, primarily through regulatory and financial instruments, but also by supporting standards for electronic communication between the actors. Many physicians (specialists and GPs) run private practices and purchase ICT solutions independently. The government, through the Directorate of Health (from now on referred to as the Agency), has in the last few years taken a more pro-active role in developing national e-health solutions, such as e-prescription, a national summary care record, and web-based health services for citizens. Lately, the e-health related units of the Agency were detached from the overall organization and formed the "e-Health Directorate" which was established on 1.1.2016.

\subsubsection{The Digital Infrastructure for Healthcare in Norway}

In Norway all GPs offices, hospitals and nursing homes have Electronic Patient Record systems (EPRs). The communication across organizations is supported by a dedicated secure network called Norwegian Health Network (NHN). NHN was established in 2004 by the Regional Health Authorities. NHN was created by harmonizing and consolidating previous existing regional broadband networks, and by pursuing national standards for electronic communication in the health sector. Initially, NHN was used to connect hospitals and gradually it was expanded to GPs, community health centres, nursing homes and recently also pharmacies. All parties sending or receiving electronic communication have their own listing in the National Register of Electronic Addresses. 
Over the years, nationally coordinated initiatives sought to shift the health sectors' communication from paper and telephone to electronic communication across the NHN. The exchange of information is currently supported by using standardized messages, for example for referrals and discharge summaries, requisitions and test results, and electronic prescriptions. It should be noted that NHN is a network dedicated to the health providers, and not intended to include communication with the patients.

In November 2012 the white paper "One citizen, One record" was issued by the Government. The strategy identified three main aims: (i) healthcare professionals shall have easy and secure access to patient-and user information; (ii) citizens shall have easy and secure access to user friendly and secure health care services online; (iii) data should be registered automatically and made available for quality improvement, monitoring, governance and research. Against this vision, a number of challenges were also identified such as under-utilized technological possibilities, many independent entities, and many systems with little integration across systems.

\begin{abstract}
Method
Data were collected via three main sources: interviews with informants from the Directorate of Health and technology providers; analysis of project documents, reports, strategy and policy documents; and observations of meetings and workshops in the context of the Digital Dialogue project. Fieldwork was conducted in the period August 2013-December 2014. The data gathered were organized by constructing the event timeline, and by writing the case narrative with attention to main events and decisions taken. The concept of installed base has guided our analysis of the data and directed our focus to how existing socio-technical arrangements have influenced the development of HealthNorway.
\end{abstract}

\title{
12.3 Case Narrative
}

\subsubsection{Phase 1: Rationale for the Development of HealthNorway and Launch}

The creation of HealthNorway started with a Government mandate in the Spring of 2010. The mandate pointed to the existence of many patient-oriented initiatives and webpages related to health, both private and public, but to the lack of a nationallevel, comprehensive initiative. Hence, HealthNorway was initiated with the aim to provide secure digital services, quality checked information on diseases and treatments, and to help citizens perceive services as available and comprehensive (Norwegian Ministry of Health and Care Services 2012). The Norwegian Government envisioned that HealthNorway will strengthen the citizen's role in healthcare by making it easier to find and choose health providers, providing access to personal health information, and by offering services self-service and self-help. 
A procurement process started in the summer of 2010 and an agreement was signed in October 2010 with a technology provider. It was made explicit that the Government required a fast pace for HealthNorway. A manager from the technology provider's side recalls: "It was very high-speed process because the Minister of Health set a politically defined date for launch and that was the 15th of June 2011".

Work on the development of HealthNorway started in the autumn of 2010. At that point, in order to meet the deadline of June 2011, it was considered realistic to adopt the simplest of a number of alternative concepts presented and aim for an information oriented portal. The underlying idea was that patients/citizens should be able to find consistent and quality checked definitions of illnesses and treatments in the information pages. The realization of this concept required substantial work in gathering material from the different health service actors and agreeing on common definitions. Reaching consensus among hospitals and other competent centers in the health sector was especially difficult for certain illnesses and diseases. Furthermore, it was decided to use as main information sources material written in English which not only required translation to Norwegian but also adaptions to convey information on the specific treatments used in Norway. On top of these challenges, the information content had to be expressed in a way that would be understandable by everyone and this created the need to involve professional writers.

Technically, HealthNorway was built upon an off-the-self platform which made possible its swift launching in June 2011. The Agency kept both the ownership and the management of HealthNorway and soon after the initial launch a new organizational unit dedicated to HealthNorway was created within the Agency. One of the Agency managers explained how work was organised: "ourmainjob is to develop HealthNorway. Everybody works on the whole of it especially the ones working with user experience, they work not in silos but as a whole group, but our budgets are organized by projects, and we have resources allocated to these different projects, but we are still working on finding a good model where we make sure that we cannot focus just on this project but we need to see the whole system for the user, and the users want that'.

\subsubsection{Phase 2: Strategy Beyond the Initial Launch}

After the launch of HealthNorway, a process started to define a new strategy toward 2017 aiming at describing the vision and action plan for further development. A manager from the technology provider's side recalls: "then we started to look into what kind of services we think we should develop on our own, what have other countries developed, what works or doesn't work, and we tried to get as much input from patients and services as we could, so we have a road map for the next five years". The strategy team received input from a range of stakeholders. They organized workshops inviting participants both within and outside the Agency, from patient organizations, to health professionals from different hospitals, and professionals working with health and communication. A manager recalls: "we tried to recruit a broad group of people, and we started out with open questions, so now we have this portal, the Minister of Health has released it, it's out there, so what should 


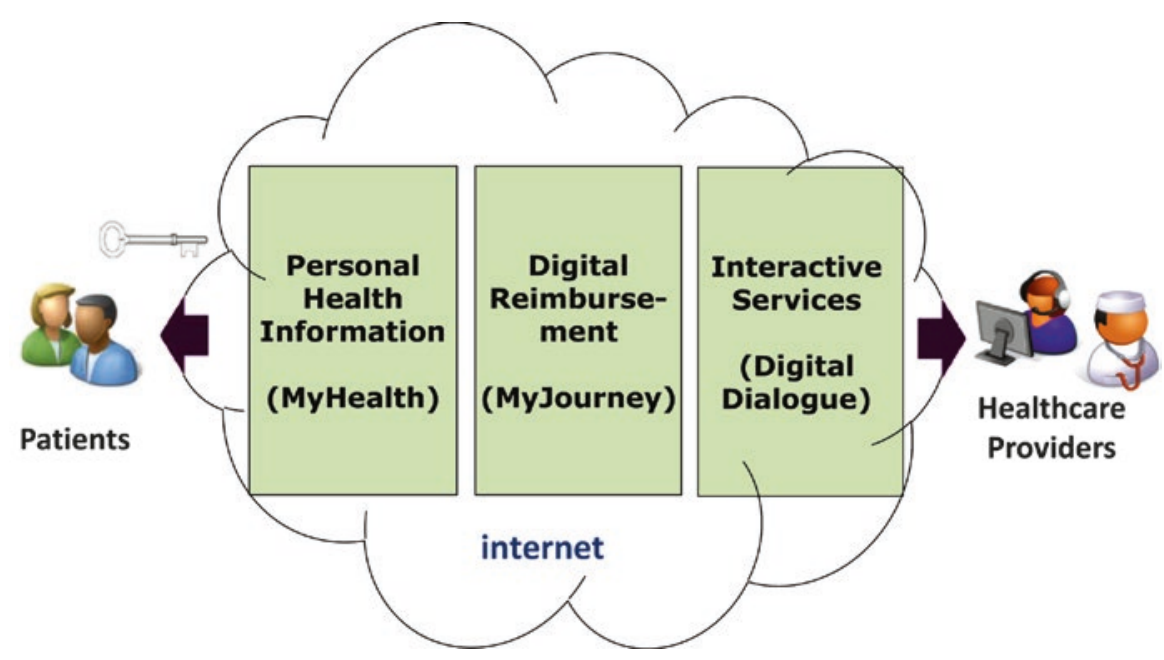

Fig. 12.1 Three priority areas for the extension of HealthNorway

we fill it with now, what do you need?". Thus, the development of the services on HealthNorway started as an open process.

During the fall of 2011, the strategy team planned the work for two main dimensions: information content and electronic services. It was agreed that the priority should be on designing new citizen-oriented services in line with the main strategic political goals to "reinforce patient- and users-role by making the everyday experience of healthcare easier and at the same time contribute to increase quality and effectiveness of health services" (quote from the strategy plan). The strategy was ready in February 2012, it described the services to develop and how HealthNorway will fulfil the requirements and expectations of citizens while at the same time addressing health policy objectives.

From March 2012, the strategy plan was implemented starting with a pre-study (March-June 2012) where the feasibility of three different services was assessed: My Health Information (later called My Health), My Patient Journey (for healthrelated reimbursable travel expenses), and secure messaging services between patients and healthcare providers (later called Digital Dialogue). The three service areas were considered as having a relatively high degree of maturity, potentially substantial benefits and acceptable implementation complexity in relation to other services outlined in the strategy plan. Figure 12.1 presents the three priority service areas, which are described in the following three subsections.

\subsubsection{Access to Personal Health Information}

According to the pre-study, "MyHealth Information" was a service area that would give citizens access to their personal health information. This service area was identified in the strategy for HealthNorway as well as requested by patients' and health 
professionals' organizations. The service aimed to offer citizens unified access to personal health information, independently of when and where information was produced (e.g. GP office visit, hospital stay, prescription). The pre-study team mapped different types of personal health information, and identified which information would be more relevant for citizens to access and would give more benefits (e.g. discharge letters, referrals, tests results). Also the team identified constrains in relation to e.g. ethical, legal, technical aspects.

The pre-study also mapped a number of ongoing local initiatives developing solutions for giving patients access to specific health information and met with key respective actors: a project at the University Hospital of North Norway (UNN) in Troms $\emptyset$ for online access to patient records (pilot in 2012-2013), a portal for patient - hospital communication that was already in use at Oslo University Hospital (OUH), a solution in use at Diakonhjemmet hospital in Oslo for sending electronically discharge letters to patients, a portal supporting communication between hospital, users and relatives at Sunnaas rehabilitation hospital, and a solution used by a private medical laboratory for giving on line access to laboratory test results. These were organization-based projects aimed to give patients access to specific health information. The HealthNorway team also looked at international experiences related to sharing health information with patients. A case considered interesting in the context of public healthcare was the national health portal in Denmark.

In addition to these solutions, a number of ongoing national initiatives were identified which aimed to give access to specific health information such as Summary Care Records, active prescriptions "My Prescriptions", vaccination "My Vaccines" records, and expense reports "My Expenses". These solutions had at the time of the study different levels of maturity. The Summary Care Record was planned to start piloting in September 2013, while My Prescriptions, My Vaccines, and My Expenses were already in use. These solutions provided access to information residing at national-level data repositories. In the prestudy it was decided that for the short term, MyHealth Information would include the existing services (e.g. My Prescriptions) and also the Summary Care Record for users in the pilot area. The pre-study also indicated the need to consider the prospect to incorporate local (mostly hospital-based) ongoing initiatives. Such local initiatives were the one by UNN for providing access to the patient records, and the OUH initiative that supports patient access to discharge letters.

Another key consideration of the pre-study was the fulfilment of the legal conditions for offering access to personal health information. It was decided to allow citizens themselves to "opt-in" on a voluntary basis for accessing electronically personal health information (through an individual consent). Furthermore, security level 4 would be required. This is the highest security level defined in the "Framework for Authentication and Non-Repudiation in Electronic Communication in and with the Public Sector" which is maintained by the Agency for Public Management and eGovernment (DIFI) and contains overall guidelines for public agencies when it comes to security for electronic communications. 
The pre-study concluded that the services were to be developed over time and it advised to start with services most readily available, where information elements are structured and standardized.

\section{Digital Support for Reimbursing Health Related Travel Costs}

The second service area presented in the pre-study was "Patient Travel". This service aimed to simplify the administrative process of requesting reimbursements for travelling to health services. In Norway patients have the right to reimburse all expenses related to travelling "to and from" health service providers, including both primary care and specialists, and for travels to and from rehabilitation services. There are significant volumes of reimbursement claims processed annually so the simplification of the related processes can contribute to substantial cost reductions for the government and service improvement for the citizens. The process in place was paper-based and with very high daily volumes of letters to be processed manually. Every day the central office would receive about $100 \mathrm{~kg}$ of post and send out a similar amount. After each travel, patients would fill a paper form, attach a certification of their visit, receipts and relevant documentation, sign and post to the national center for patient travels. After the processing of their reimbursement claim, they would receive a letter with the decision in the mail, and the sum would be transferred to their bank account. This process made reimbursements slow and complex.

The aim of "Patient Travel" was to create an online electronic form for requesting reimbursement and make the service both more efficient for the public administration and more accessible to patients. The long term goal defined was to have a mechanism in place that would trigger reimbursements automatically without the need of having patients to proactively claim the funds that they are entitled to receive. The pre-study concluded that a pre-project had to be initiated in order to identify the legal, economical, functional and technical requirements for the digitization of the current process and the development of the new electronic service.

\section{Digital Communication Between Patients and Healthcare Providers}

An overall mapping of services that could make use of secure digital communications between patients and healthcare providers was included in the pre-study. The intention was to make everyday life easier for patients, and to a certain degree also for health providers. A key requirement defined was the user-friendliness of the new services and the assurance that they will be intuitive, clear and adapted to different individual needs.

The pre-study focused on asynchronous communication between patients and their health providers in cases where a patient-provider relation was already established, for instance between patients and their General Practitioner (GP). It indicated also that secure message services should initially target primary care: "The reason is that user-initiated communications will intervene significantly in the work processes, organization and ICT support, and that this seems more complex for hospitals than for primary care. For contracted specialists it will be 
considered to implement certain dialogue on an equal footing with primary care" (quote from the pre-study). The services considered were the ones judged as generic and applicable to different health provider groups and different health institutions. The study clearly stated: "processes around appointments, e-consultation and document/form exchanges are generic processes that can be transferred from one area to another".

It was concluded that communication services will be developed first for supporting GP-patient interactions. Specifically, the pre-study specified the need to develop the following electronic services: renewal of prescriptions, appointment reservation and dialogue messages. In addition, the pre-study identified the need to create a storage solution for the messages of the dialogue service. If messages were to be stored only in the GPs' Electronic Patient Record systems (EPRs) it would be difficult to ensure uninterrupted accessibility by patients. Another aspect discussed in the pre study was how to make patients' messages available to GPs and what would be the role of the EPR vendors in setting up the services. The pre-study stated that it was not yet clear how HealthNorway would relate to private actors, such as vendors, but it recognized the importance to enter in dialogue with them for defining an integration strategy between HealthNorway and existing systems used by health personnel.

Different options were considered. One possibility was to link the HealthNorway with the existing private eHealth portals already used by several GP offices for their communication with patients. Some of these solutions had functionality for booking appointment, and renewing prescriptions and medical certificates. These solutions and their users - GPs, administrative personnel in the GP offices, and patients - could be a possible installed base for the new services. Technically, this would require to redirect users from HealthNorway to the private portals. It was decided not to opt for this solution and instead to link the healthcare providers' side with HealthNorway via the existing GPs' EPR systems.

One reason for this decision was that although all GP offices have an EPR system, not all of them offer electronic services to their patients (Vassilakopoulou and Grisot 2014). A participant of the pre-study from the Agency recalls: "It was a large discussion about how could it actually be possible to use what was already in the market and how would actually turn out before the citizens. (...) how would the user experience be in that case, and how would the security be". It was considered best if HealthNorway created an equal right and opportunity for all regardless of where they lived, or the kind of system their doctor had. Another reason was that the future plan for HealthNorway was to provide a comprehensive interface for patients to access organized information from multiple different sources. This comprehensive interface would gradually support the creation of a timeline as organizing principle for messages, prescriptions, certificates, appointments, diagnoses, and discharge letters in one place. Thus, it was important to not redirect to third parties in order to avoid missing pieces of the overall communication history. Furthermore, redirecting to third parties would 


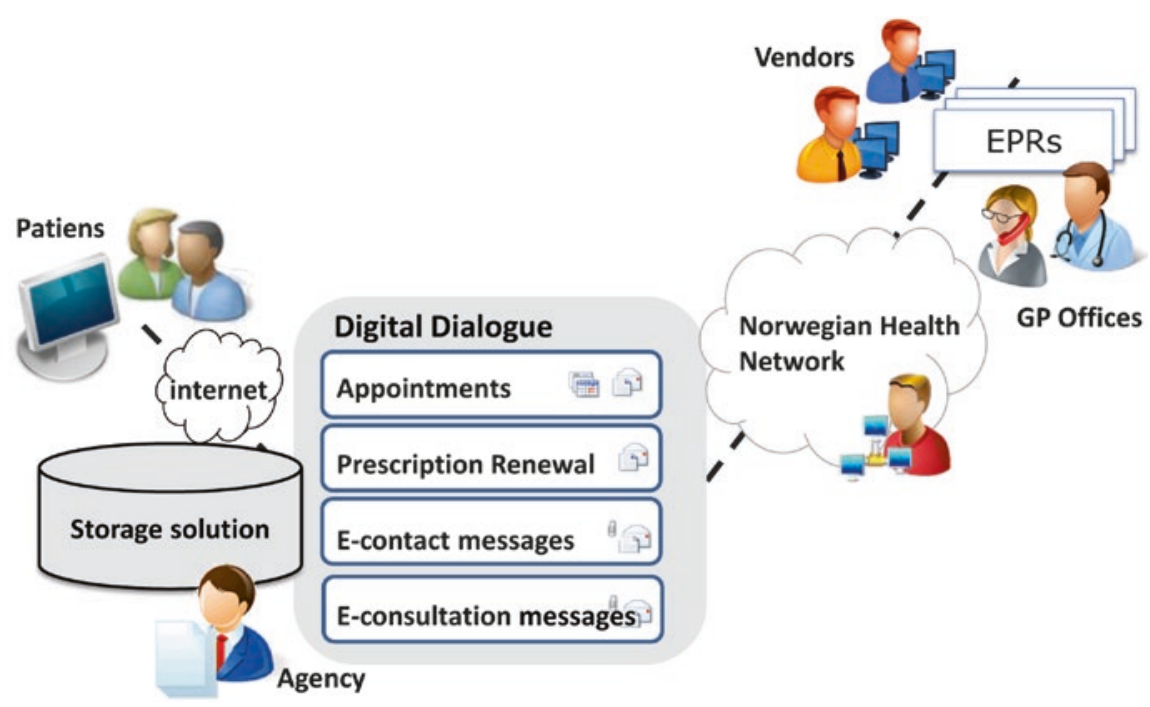

Fig. 12.2 Digital communication between patients and GP offices

harm the uniformity of the user experience and would create complications in security handling.

The decision to link the healthcare providers' side with the patients via the existing GPs' EPRs created the need to work with the EPR vendors and enroll them in the project. However, it was not certain that all EPR vendors would be willing to participate. Some were small vendors who provided EPR systems to GPs but not patient portals. One pre-study participant recalls that for them this was a "fantastic opportunity to join, to hop on the boat". But other vendors had their own patient portal and questioned "how should we earn money in this market, because what's happening now is that we have our patient portal, with other services that you say that you want to develop we have them in place already, it's not big, we have them spread all over, but now you want us to just blend in with the others and that you just take over the portal side". It was realized that having to rely on EPR vendors' collaboration was a major risk but it was decided that the expected benefits justified the risks. Figure 12.2 presents the overall arrangement decided for the digital communication between patients and GP offices.

\subsubsection{Phase 3: Mature Services and Further Development Through Alliances}

In August 2013, the secure service MyHealth was launched. By logging-in citizens could access the following main services: My Expenses, My GP, and My Prescriptions. Additionally, a number of other simpler services were offered such as 
electronic forms for ordering the European health insurance card and submitting notifications of experienced drug side effects. The highest security level for patient authentication was ensured using three alternative and already existing eID solutions: BankID (the Norwegian Banking Sector's common digital authentication and online signing solution), Buypass (jointly owned by Norway Post and Norwegian Lottery) and Commfides (a private solution). At a later point, other functionalities were added, for instance a service called "About me" where citizens could access their personal and contact information from the central National Registry and the GP Registry.

In November 2013, access to the Summary Care Record was added to MyHealth for the inhabitants of the pilot area. This service was the result of a project run by the Agency with the aim to support health personnel in emergency situations with access to patients' core medical information. The Summary Care Record contains key patient health information entered by GP/attending physician, and it retrieves prescription history, and information from national registries (e.g. the history of admissions and hospitalizations in the specialist health service is retrieved from the Norwegian Patient Registry (data from 2008)). In MyHealth, citizens can access the record, see the access log, register new information such as primary contact person, and disease history (structured selections), or they may opt out of the record entirely.

During autumn 2013 and the first semester of 2014, HealthNorway was redesigned, and in June 2014 relaunched with a new interface supporting mobile use. It was also migrated to a new version of the underlying technical platform, with a new search engine. This was important for improving usability and also, for ensuring the long-term evolvability of the platform.

In the same period, two local initiatives aiming for patient-oriented services started. Both initiatives were aligned with two priority areas of HealthNorway providing personal health information and providing interactive services between patients and health providers - and contributed to its further development.

The first initiative was taken by UNN (University Hospital of North Norway in Troms $\varnothing$ ) that decided to offer patients access to their hospital records. A survey revealed that most patients requesting copies of their hospital records would like to have them electronically. A project to develop a "proof of concept" solution for online access to patient records was launched in March 2012. The project was managed and financed by UNN and was implemented in close collaboration with the software company that provides the EPR for hospitals in the North Region. The EPR provider developed a solution for extracting data from medical records based on the specifications provided by UNN and also, based on the national recommendations provided by the Agency. From March 2014, the North Regional Health Authority took over the project. The online record access service was tested with 500 end-users and soon after testing it was made available to all residents of North Norway (in December 2015). The new electronic service allows patients to 
electronically retrieve health record documents from public hospitals in North Norway. Since 2015, the service can be accessed by patients through the secure HealthNorway interface.

The second initiative was a project initiated by the West Regional Health Authority who wanted to facilitate message exchanges between hospitals and patients. This was motivated by the need to reduce the number of appointment "no-shows" improving the utilization of available resources. In 2012 there were 82,000 missed scheduled appointments in the Western Region resulting in a significant waste of resources. In September 2013, the Agency endorsed the initiative and started a project to provide electronic support for the communication between patients and hospitals aiming for better coordination between the two parties. The project delivered a new electronic service for patients that have appointments at hospitals in the Western Region. These patients can have an overview of their appointments, confirm their attendance and send messages to the hospital (e.g. for changing the appointment time or even deciding to cancel the appointment altogether). Additionally, patients can check the status of their referrals for specialist services within the hospitals in the Region. For each referral they can check when it was received by the hospital, if it is still being processed or if a time slot has already been allocated to the. This service was offered in HealthNorway in 2015. By endorsing and including the two regional initiatives, HealthNorway is gradually becoming a universal interface to patient oriented electronic services in Norway.

In 2014 the Agency collaborated with the Norwegian National ICT (NICT) which is the interest body for information and communication technologies in the specialist healthcare sector formed by the four Regional Health Authorities. The collaboration aimed to the identification of citizens' needs for digital services in specialized care. The objective was to obtain insights for further developing HealthNorway and making it an entry point for both primary and specialized digital health services. The result was an extensive mapping and analysis of users' needs involving health personnel, citizens and management bodies of the health regions. The analysis ended up with the identification of 11 priority service areas (for example, services for supporting hospital appointment booking including preparation and follow-up after visits, services for providing an overview of visited health providers). This work informed the formulation of a strategy for digital specialist health services for citizens up to 2020, and led to the formation of a specific project on digital citizen services for the specialist sector (named the DIS) which started in January 2015. The project is expected to launch new electronic services in 2017.

In Fig. 12.3, we provide an overview of key milestones in the evolution of HealthNorway. Additionally, in Fig. 12.4, we present the time series of users per month from July 2011(right after the portal launch) till August 2016. HealthNorway managed to attract users' interest over the years and the monthly number of users is now about 1,4 million (the total population of Norway is approximately 5 million). 


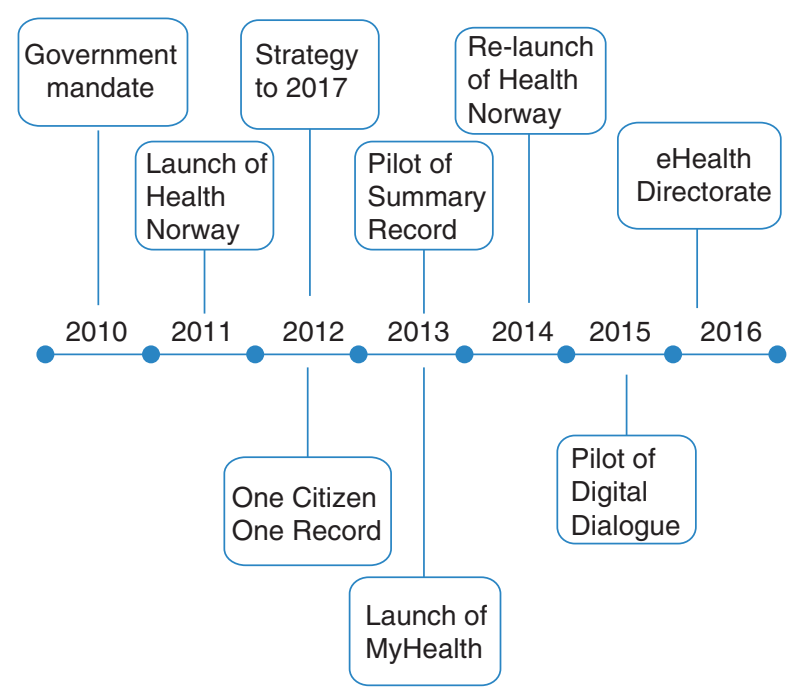

Fig. 12.3 Key milestones in the evolution of HealthNorway

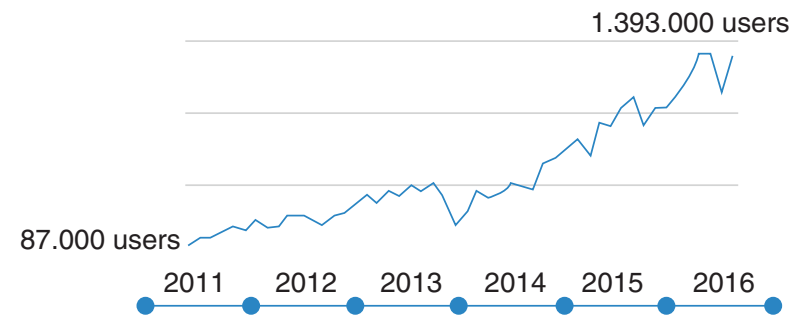

Fig. 12.4 Users per month from HealthNorway launch till Aug 2016

\subsection{Analysis}

In the paragraphs that follow we analyse how the installed base influenced the evolution of the portal, and how designers have engaged in "cultivation" strategies (Dahlbom and Mathiassen 1993; Ciborra 1997; Ciborra and Hanseth 1998). The installed base consists of various existing information systems, work and information practices, legal frameworks, standards and institutional conventions which relate to patient-oriented electronic health services. When faced with the installed base, the team building HealthNorway took different strategic decisions on what to "grow" in the new eHealth solution and what to redesign and substitute. This process stretches in time. The development of HealthNorway is not an "one-off" effort but entails a long lasting process of continuous launching of new services and further refinements. Thus, HealthNorway's services, contents and architecture were not fully specified and designed beforehand, but gradually grew by taking into account the overall government aims for patient oriented electronic services, the desires of the prospective users (citizens and healthcare providers) and the 
opportunities and limitations of the healthcare milieu. This process developed according to different reasons as for instance the qualities (e.g. scalability) and levels of maturity of existing components.

The strategy after the initial launch was to grow by adding relevant electronic services. Specifically, three service areas were identified and prioritized: (i) access to personal health information, (ii) travel reimbursements, (iii) digital dialogue with health practitioners. The Agency approached the design of these new services first by mapping existing technologies and information practices, and making sense of the existing institutional arrangements. In our analysis we interpret the ways the three service area were grown, as the enactment of strategies to deal with different aspects of the installed base.

In the case of access to personal health information, My Health, the pre-project team mapped a set of already existing projects, some of which had already implemented solutions on national level for giving access to selected personal health information, and were accessible via various health providers' websites. For instance, ePrescription was rolled out on a national scale and citizens could see their active and old prescriptions. On a different website, it was possible to log-in and change GP. The approach here was to include in HealthNorway services that were already developed in projects run previously by the Agency itself or by other public health organizations. In addition, the strategy was to create an area - My Health where types of access to personal health information could be easily added, and which would work as central access point for citizens. Following this strategy, after the launch, My Health was gradually enriched by offering even services which were not yet nationally scaled and were only offered to citizens in specific geographical areas. Thus, the Agency developed My Health by including existing services which acted as a strong installed base to build on. This approach allowed reaping benefits in the short term. Indeed, this service area was launched relatively swiftly and made available in August 2013. The Agency followed the more long-term strategy to gradually complement the installed base of existing services by adding new services according to the long-term visions of offering access to comprehensive personal health information.

In the case of "Patient Travel" the aim was to simplify the administrative process of requesting reimbursements for travelling to health services. In this case the installed base consisted of existing work, communication and information practices and of a paper-based system (citizens sending forms to the reimbursement office). In this case, the Agency decided for a digitization of the existing arrangement, adding brand new digital capabilities to the installed base that could serve as substitutes the traditional paper-based capabilities with the aim to eventually phase them out. The core idea was that an online electronic form would be made available for citizens requesting reimbursement to facilitate the transition from purely paper-based processes to digital supported ones. Digitization processes are seldom straightforward transpositions of pre-existing non-digital arrangements. The participants in the pre-study were aware of the possible complications and they defined as a next step the analysis of the legal, economical, functional and technical requirements. Indeed, this service area is the least developed today (January 2016). The digitization necessitated changes in the corresponding regulations that were adopted by the 
Norwegian Parliament in June 2015. These changes included the legal ratification of electronic claims submission for the patients that choose to do so, a new provision that stipulated that patients do not have to provide travel evidence as this would be retrieved from the registries and a new rule for covering a standard mileage allowance instead of the cost of cheapest scheduled public transport. It is envisaged that the electronic service will be made available in HealthNorway in 2016.

In the case of secure digital communications between patients and healthcare providers the task was to design and create a novel service, which would complement other existing modes of communicating such as visits and phone conversations. In this scenario, the team had different options for the development of the service. The team examined existing web-based services that some GP offices already offered, for instance for requesting appointments or renewing prescriptions. However, this base was considered weak because it was heterogeneous (many different and diverse websites), not secure enough (not all private eHealth portals in the market had implemented the security level required by law), and the user experience was evaluated as becoming too complicated and fragmented in a scenario where the national portal would redirect to the each GP's own page. Alternatively, the approach adopted was to work with the installed base of EPRs in use in the GP offices (all GP offices in Norway have an EPR system), and extend them to support the dialogue service. In this case the installed base included also the capabilities and knowledge of EPR vendors about GP office practices. However, this entailed a complex coordination effort. Indeed, the development of this service proved challenging and it necessitated the development of a sensitivity to the constraints and singularities of all the actors enrolled and the emerging interdependencies (Grisot and Vassilakopoulou 2015). As of early 2016, the new communication services are being piloted and it is expected that they will be fully launched soon.

Overall, the analysis of how the installed base has influenced the evolution of HealthNorway in the three different service area, show that the Agency engaged in different ways with the existing installed base, by complementing, creating substitutions, and expanding it. Overall, the analysis shows some key characteristics of cultivation strategy. First, in building HealthNorway, the Agency has deliberately engaged with the existing technology and institutional arrangements in place, and has built alliances for bringing together the efforts of distributed actors. Second, HealthNorway has expanded by orientating towards the satisfaction of concrete needs in order to motivate prospective users to adopt the new services. Third, overall changes have been incremental, exploratory and gradually intervening on various level (architecture design, user experience, technical platform) while keeping a coherent vision.

\subsection{Discussion and Conclusion}

In this chapter, we explored the different approaches employed for advancing the development of the Norwegian patient oriented healthcare portal (HealthNorway) that was initially launched with a limited functionality. The aim for HealthNorway is to eventually become a single, national point for patient oriented electronic health 
services. This aim created the need to engage with the installed base in a variety of ways and with different purposes.

We identified that the overall strategy employed entailed starting with concrete needs, capitalizing on what is already in place and proceeding in an incremental and exploratory way. This seems to be a prudent strategy. Prior information infrastructures' literature has indicated that the successful development of information infrastructures such as the Internet, mobile phone platforms and healthcare-specific arrangements has been achieved by following similar strategies (Hanseth and Lyytinen 2010; Aanestad and Jensen 2011; Aanestad and Hanseth 2002). Our findings are specific to processes for advancing the development of infrastructures that are already in place, nevertheless, they are congruent with recent findings by Grisot et al. (2014) that identified three different types of infrastructure innovation: in, of, on infrastructures. Innovations of infrastructures are about implementations of totally new infrastructures, innovations in infrastructures concern replacements/modifications of an infrastructure's existing components without changing the architecture and innovation on infrastructures concern additions of new components on top of what exists. Similarly, in our case, complementing the installed base entails finding ways to realize some of its latent potential by embracing capabilities already developed by others and linking to them. This is an approach that can yield benefits in the short term. Creating substitutes within the installed base entails creating new working arrangements and this involves encountering and handling sociotechnical complexity. Hence, this approach requires the dedication of efforts for a considerable length of time. Finally, extending the installed base entails complex coordination and enrolling efforts for the multiple actors that control distributed information infrastructure resources.

Acknowledgments This research was part of the Responsive Architectures for Innovation in Collaborative Healthcare Services (REACH) project, funded by Norwegian Research Council, VERDIKT program (project nr. 213143). We are grateful to the members of the team working on Helsenorge.no who participated in the study.

\section{References}

Aanestad M, Hanseth O. Growing networks: detours, stunts and spillovers. In: Cooperative systems design. A challenge of the mobility age, Proceedings of the Fifth International Conference on the Design of Cooperative Systems (COOP 2002), Saint Raphaël, France, 4-7 June 2002. Amsterdam: IOS Press; 2002. p. 38-49.

Aanestad M, Jensen TB. Building nation-wide information infrastructures in healthcare through modular implementation strategies. J Strateg Inf Syst. 2011;20:161-76.

Ciborra C. De profundis? Deconstructing the concept of strategic alignment. Scand J Inf Syst. 1997;9:2.

Ciborra C, Hanseth O. Toward a contingency view of infrastructure and knowledge: an exploratory study. Proceedings of the International Conference on Information Systems, Helsinki, Finland, December 13-16. Association for Information Systems. 1998.

Dahlbom B, Mathiassen L. Computers in context: the philosophy and practice of systems design. Cambridge, MA: Blackwell Publishers; 1993.

Grisot M, Vassilakopoulou P. The work of infrastructuring: a study of a National eHealth Project. ECSCW 2015: Proceedings of the 14th European Conference on Computer Supported Cooperative Work, 19-23 September 2015, Oslo, Norway. Springer; 2015. 
Grisot M, Hanseth O, Thorseng A. Innovation of, in, on infrastructures: articulating the role of architecture in information infrastructure evolution. J Assoc Inf Syst. 2014;15:197-219.

Hanseth O, Lyytinen K. Design theory for dynamic complexity in information infrastructures: the case of building internet. J Inf Technol. 2010;25:1-19.

Norwegian Ministry Of Health And Care Services. Stortingsmelding nr. 9: Én innbygger - én journal. Digitale tjenester i helse- og omsorgssektoren. 2012.

Vassilakopoulou P, Grisot M. Infrastructures for patient-centeredness: connecting novel and existing components to serve strategic agendas for change. European Conference on Information Systems - ECIS 2014. Tel Aviv; 2014.

Open Access This chapter is distributed under the terms of the Creative Commons AttributionNonCommercial 2.5 International License (http://creativecommons.org/licenses/by-nc/2.5/), which permits any noncommercial use, duplication, adaptation, distribution and reproduction in any medium or format, as long as you give appropriate credit to the original author(s) and the source, provide a link to the Creative Commons license and indicate if changes were made.

The images or other third party material in this chapter are included in the chapter's Creative Commons license, unless indicated otherwise in a credit line to the material. If material is not included in the chapter's Creative Commons license and your intended use is not permitted by statutory regulation or exceeds the permitted use, you will need to obtain permission directly from the copyright holder. 